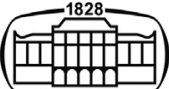

AKADÉMIAI KIADÓ

Journal of Behavioral Addictions

9 (2020) 2, 325-338

DOI:

$10.1556 / 2006.2020 .00020$

(c) 2020 The Author(s)

\section{FULL-LENGTH REPORT}

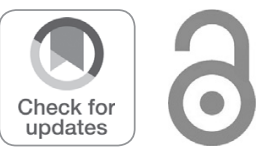

\title{
Altered brain network topology related to working memory in internet addiction
}

HONGXIA WANG ${ }^{1,2}$, YAN SUN ${ }^{1 *} \odot$, FAN LAN $^{1}$ and YAN LIU ${ }^{1}$

${ }^{1}$ School of Psychology, Liaoning Normal University, Da Lian, 116029, China

${ }^{2}$ Department of Psychology, Renmin University of China, Beijing, 100872, China

Received: September 26, 2019 • Revised manuscript received: March 28, 2020; April 13, 2020 • Accepted: April 15, 2020 - Published online: July 7, 2020

\section{ABSTRACT}

Background and aims: The working memory (WM) ability of internet addicts and the topology underlying the WM processing in internet addiction (IA) are poorly understood. In this study, we employed a graph theoretical framework to characterize the topological properties of the IA brain network in the source cortical space during WM task. Methods: A sample of 24 subjects with IA and 23 matched healthy controls (HCs) performed visual 2-back task. Exact Low Resolution Electromagnetic Tomography was adopted to project the pre-processed EEG signals into source space. Subsequently, Lagged phase synchronization was calculated between all pairs of Brodmann areas, the graph theoretical approaches were then employed to estimate the brain topological properties of all participants during the WM task. Results: We found better WM behavioral performance in IA subjects compared with the HCs. Moreover, compared to the HC group, more integrated and hierarchical brain network was revealed in the IA subjects in alpha band. And altered regional centrality was mainly resided in frontal and limbic lobes. In addition, significant relationships between the IA severity and the significant altered graph indices were found. Conclusions: In conclusion, these findings provide evidence to support the notion that altered topological configuration may underline changed WM function observed in IA.

\section{KEYWORDS}

internet addiction, working memory, 2-back, eLORETA, graph theory

\section{INTRODUCTION}

The internet playes an increasingly important role in public life, but excessive use of the internet may lead to internet addiction (IA), which is usually defined as a person's inability to control his or her use of the internet; eventually leads to some negative effects include emotional, social and mental consequences in a wide range of areas of daily activities (Spada, 2014; Young, 1998). However, prolonged internet using is positive or negative is still controversial. There are two theories that hold different views, one is the "displacement hypothesis", and the other is the "enhance hypothesis." The displacement hypothesis believes that the use of the internet may hinder people's social development, making them experience more loneliness and depression (Kraut et al., 1998). The enhance hypothesis is a theory that holds a effective view of the internet. It believes that the internet can break through the obstacles of time and space, enlarge people's social connections and interpersonal intimacy (Kraut et al., 2002). Furthermore, in the field of cognitive neuroscience, the extent to which prolonged internet using 'damage the brain' or 'boost the brain power' is also uncertain. A few studies have reported that long-term different types of internet activities can be expected to promote positive neurological changes in the brain system, such as video games (Bavelier et al., 2011; Han, Kim, Bae, Renshaw \& Anderson 2015b) and general IA including various internet applications (Liu, Gao, Osunde, $\mathrm{Li} \& \mathrm{Li}, 2010$ ). But, on the other hand, there are also opinions that the working memory (WM) of internet sex addiction interfered by pornographic picture cues (Laier, Schulte, \& Brand, 2013). Problematic internet game play is often accompanied by higher impulsivity (Hong, Sun, Bae, \& Han, 2018) and poorer response inhibition 
(Chen et al., 2015; Ding et al., 2014). Moreover, unspecified internet-use disorder is also associated with robust cognitive deficits (Choi et al., 2014; Nie, Zhang, Chen, \& Li, 2016; Zhou, Zhou, Li \& Wang, 2014; Zhou, Zhou, \& Zhu, 2015).

Executive function and WM are essential for cognition (Zhou, Zhou, Li \& Wang, 2014), WM is an executive function that permits the maintenance of the information needed to execute high-level plans, which is vital for reasoning, learning and language comprehension (Nie, Zhang, Chen, \& Li, 2016). WM is a memory system that allows temporary storage and processing of limited information in the mental workspace (Baddeley, 2012). Cognitive studies have demonstrated that WM ability decreased in IA individuals like alcohol-dependent patients (Zhou, Zhou, Li \& Wang, 2014) and pathological gambling patients (Zhou, Zhou, \& Zhu, 2015). Nie, Zhang, Chen \& Li (2016) found subjects with IA demonstrated impaired WM that might be related to poor inhibition especially associated to internetrelated stimuli. However, other researchers found that the WM ability of behavioral addicts was not significantly different from that of healthy subjects (Jasper, 2016; Yan et al., 2014).

Although accumulative behavioral studies suggested the altered WM functions closely associated with IA, how the brain characteristics are modulated by the memory load is still unclear. The examination of the human brain functional connectome with electroencephalogram (EEG) and graph theory techniques are beneficial research approaches in present neuroscience (Franciotti et al., 2019; Gomez-Pilar et al., 2018; Vecchio et al., 2014, 2016, 2017). Some studies have confirmed the validity of the graph theory to investigate the brain topology for working memory performance (Cao et al., 2014; Dai et al., 2017; Finc et al., 2017; Liang, Zou, He, \& Yang, 2016; Sun et al., 2014; Yang et al., 2020). Many prior studies used EEG technology to study the brain functional connectome of IA at resting state (Kim et al., 2017; Lee et al., 2014; Park et al., 2017; Wang \& GriskovaBulanova, 2018). And there are also event-related potential (ERP) study revealed the WM damage in IA (Xiong \& Yao, 2010). Less interest has been directed to the examination of the IA participants' brain topologies constructed from EEG data collected when performing a task, which is vital due to the fact that certain connectivity features during a task may additionally no longer be evident at relaxation (Bilek et al., 2013; Pezawas et al., 2005). It is essential to fill this gap in the literature in order to determine the brain topological configuration in IA individuals during the WM task.

Graph theory is a mathematical method that can evaluate the characteristics of structures that can be modeled as sets of vertices (i.e., brain regions) and edges (i.e., functional connections) (Brier et al., 2014). This approach is a prospective way to describe brain functional organization (Bassett \& Bullmore, 2006) and correlate it with behavioral or task-related performances (Vecchio et al., 2017). The application of graph theory in IA has provided conflicting results. Some studies concluded that the network topology alterations of IA were tiny, significant changes were only observed for regional nodal metrics, there was no difference in global network topology between the IA and HC groups
(Lee et al., 2017; Wee et al., 2014). In another study, the IA was characterized by a less global integrated network organization with decreased efficiency and increased shortest path length (Zhai et al., 2017). Considering the extensive WM alteration, it may be anticipated that IA subjects would display changes in brain network connectivity and topology.

The functions of frontal lobe consisting of strategic planning, organized searching, using environmental feedback to change cognitive patterns, guiding behavior to reach a goal, and regulating impulsive response (Zhou, Zhou, Li \& Wang, 2014). An updated Person-Affect-Cognition-Execution (I-PACE) model for addictive behaviors was proposed in a recent review (Brand et al., 2019), indicating the imbalance between limbic/reward-oriented brain circuits and prefrontal control in behavioral addictions. Previous researches stress the vital function of prefrontal-cortexrelated inhibitory control during the IA process (Han et al., 2011; Meng, Deng, Wang, Guo, \& Li, 2015). Moreover, subcortical structures, such as limbic, play a supporting role in executive and WM functions (Brooks, Funk, Young, \& Schiöth, 2017; Huang et al., 2017; Ladouceur et al., 2013). In current study, EEG data was recorded during 2-back task and transformed into the source space using the exact Low Resolution Electromagnetic Tomography (eLORETA), avoiding the feasible deviation in inferring the locations of the sources within the brain responsible for the observed activity on the scalp (Ewald, Marzetti, Zappasodi, Meinecke, \& Nolte, 2012; Scheeringa et al., 2009) and the limitation of the lower temporal resolution of functional magnetic resonance imaging (fMRI) technology (Dai et al., 2017). Therefore, the comprehensive method in the EEG source space that accurately describe the regional locations of the brain has the potential to help us shedding more light on the mechanism of IA participants' WM processing.

In this study, using the graph theoretical framework, we explored the brain topology of the IA and HC participants during the WM task in different frequency bands (delta: 1-4 $\mathrm{Hz}$; theta: 4-8 Hz; alpha: $8-12 \mathrm{~Hz}$; beta: $12-30 \mathrm{~Hz}$; gamma: $30-45 \mathrm{~Hz}$ ). Subsequently, the relationship between extracted neurophysiologic indices and subjects' IA severity was assessed to explore to what extent the estimated EEG networks topology would account for the behavior of IA participants. Based on the previous discoveries, we hypothesized that (1) the WM performance of IA group would be different from the HC group; (2) the IA participants would show altered global topology relative to the HC participants, and the frontal and limbic areas related to WM would show different centrality between the two groups; (3) the network properties would be linked to IA severity.

\section{MATERIALS AND METHODS}

\section{Subjects}

A sample of 24 IA (14 males and 10 females; mean age $=$ $20.58 \pm 2.39$ years) and 23 matched HC participants (10 males and 13 females; mean age $=21.13 \pm 2.51$ years) with 
normal or corrected-to-normal vision from Liaoning Normal University were recruited in this study. All were right handed as defined by the Edinburgh Handedness Inventory (Oldfield, 1971). Participants were recruited through word-of-mouth and social networks, and they would receive a short telephone interview before inviting to participate in the experiment to ensure that they met all inclusion criteria in the present study, i.e., those subjects who had a history of alcohol, nicotine or drug use; had symptoms of mental illness, such as depression, anxiety or attention-deficit/hyperactivity disorder (ADHD); were pregnant or menstruating women; had a history of brain injury were excluded. According to a previous IA study (Yuan et al., 2011), we chose IA subjects who spent more than $10 \mathrm{~h}$ per day, 6 days per week on internet, and whose internet addiction test (IAT) score is greater than 50. HCs who spent less than $2 \mathrm{~h}$ per day on the internet were selected. The HCs were also tested with the IAT criteria that less than 50 . The specific sample information was shown in Table 1.

\section{Internet Addiction Test (IAT)}

The IAT was compiled by Young (1998) at the University of Pittsburgh. The scale is self-reported and contains 20 items. The title options for rarely, occasionally, sometimes, often and always are scored as 1,2, 3, 4 and 5 points, respectively. The total score is $20-100$, a higher total score indicates increased severity of addiction to internet-related activity: 20-49 for normal users, 50-79 for excessive internet addicts, and $80-100$ for severe internet addicts. This measure has demonstrated good reliability and validity in Chinese (Zhou, Li, Xian, Wang, \& Zhao, 2017).

\section{Data acquisition and experimental paradigm}

A digital EEG recording system produced by the BrainProduct company (German) was adopted. The 64-channel electrode cap was complied with the 10-20 international system. Both the vertical and horizontal channels of the electro-oculogram (EOG) were recorded simultaneously to monitor the eye movements and blinks. The unipolar reference region was linked at the right and left earlobes, and the ground electrode was located at the AFz (A-Ear lobe, FFrontal lobe, z-zero, referring to an electrode placed on the midline). The sampling frequency was $500 \mathrm{~Hz}$, and the electrode impedance was less than $10 \mathrm{~K} \Omega$.

EEG data was acquired for each subject when they performed the 2-back WM task. N-back paradigm was adopted; the paradigm requires participants to compare the currently presented stimulus letter with the $\mathrm{n}$ stimulus letters in front of it. In this study $n=2$, the subjects needed to compare the currently presented letter stimuli with the two trials before it, and were instructed to indicate whether the current letter was the same (Target, key-press "F") or different (Non-Target, key-press "J") as the two trials before it. Subjects were not required to respond to the first two trials of each block.

Stimulus were presented on a windows computer via Eprime 1.1 software (https://en.freedownloadmanager.org/ users-choice/E-prime_Software_Version_1.1.html). The experimental guidance was presented in the center of the screen. After the participants fully understood the experimental instruction, pressed the Q key to start the experiment. The experiment was divided into practice experiment and formal experiment. The practice experiment required the subjects to complete the 2-back WM task in order to ensure that they fully understood the purpose of the experiment and the correct response button and then began the formal experiment. The formal experiment consisted of 10 blocks, each block consisted of 16 trials, the probability of target condition was 0.33 and the stimulus letters would be randomly presented from 15 letters, including $\mathrm{A}, \mathrm{F}, \mathrm{H}, \mathrm{I}, \mathrm{J}$, K, L, M, O, P, Q, R, S, U and Y. Each participant was requested to complete 2 sessions of the 2-back task in a pseudorandom order. After a half of blocks were completed, the subjects took a break of about $2 \mathrm{~min}$. The subjects needed to complete 10 blocks in turn, each stimulus letter would appear $500 \mathrm{~ms}$, and accompanied by a blank screen of

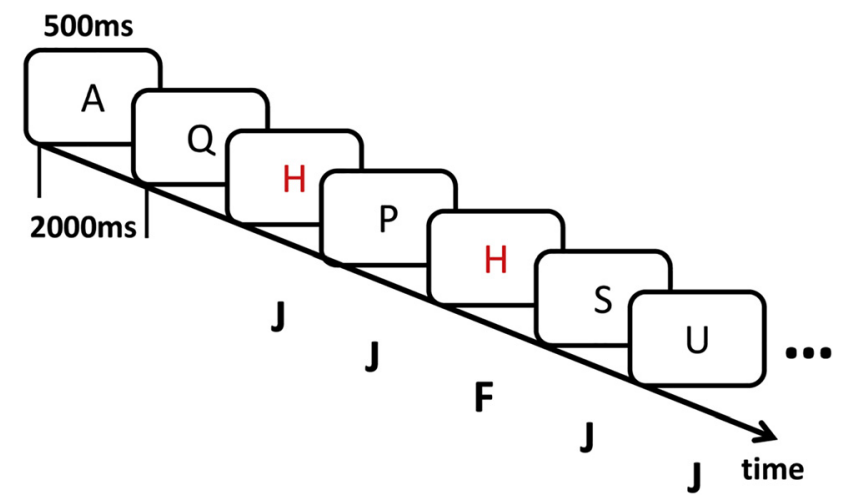

Figure 1. Flow chart of 2-back experiment. Each stimulus letter would appear $500 \mathrm{~ms}$, and accompanied by a blank screen of 2000 $\mathrm{ms}$. The subjects were not required to respond to the first two trials and need to compare the currently presented letter stimuli with the two trials before it. They were instructed to indicate whether the current letter was a target (key-press "F") or a non-target (key-press "J")

Table 1. Subject demographics for internet addiction (IA) and healthy controls (HCs)

\begin{tabular}{lccc}
\hline Items & IA $(\mathrm{N}=24)$ & HC $(\mathrm{N}=23)$ & Test values \\
\hline Sex (Male/Female) & $14 / 10$ & $10 / 13$ & $\chi^{2}=1.037, P=0.308$ \\
Age (years) ${ }^{\mathrm{a}}$ & $20.58 \pm 2.39$ & $21.13 \pm 2.51$ & $t=-0.765, P=0.448$ \\
IAT scores & $58.38 \pm 6.53$ & $35.96 \pm 7.78$ & $t=10.717, P<0.0001$ \\
Profitable hand (Right/Left) & $24 / 0$ & $23 / 0$ & - \\
\hline
\end{tabular}

${ }^{\text {a }}$ Values are expressed as the mean \pm standard deviation (SD). IAT, internet addiction test. 
$2000 \mathrm{~ms}$, the experimental procedure of WM task to deliver the paradigm was in Fig. 1. It took about $10 \mathrm{~min}$ to complete the entire experiment. During the EEG data collection, the participants were instructed to emphasize both accuracy and speed in their performance and to avoid unnecessary head movement.

\section{EEG signal processing}

Off-line EEG data for all participants were analyzed by Brain Vision Analyzer 2 software (https://brainvision-analyzer. software.informer.com/2.0/). First, data was re-referenced to the "infinity" reference provided by the reference electrode standardization technique (REST; Yao, 2001), and band pass-filtered from 1 to $45 \mathrm{~Hz}$. Data portions contaminated by eye movements, electromyography, or any other non-physiological artefact were removed using the Independent Component Analysis algorithm (Jung et al., 2001; Mantini et al., 2009). Then, the preprocessed EEG data were segmented into dozens of epochs, using the stimulus onset as a reference, including $200 \mathrm{~ms}$ before and $2300 \mathrm{~ms}$ after the stimulus onset. Here, only correct trails were selected for further analysis. Individual epochs were baseline-corrected (-200-0 ms). Data were visually inspected to remove epochs contaminated by excessive noise or with amplitude values exceeding $\pm 150 \mu \mathrm{V}$. Finally, the artefact-free epochs were exported to ASCII files.

\section{EEG cortical functional connectivity network construction}

Exact low resolution electromagnetic tomography (eLORETA) source localization technique was adopted in current study based on multichannel surface EEG recordings. The head model of eLORETA and the electrode coordinates are based on the Montreal Neurological Institute average MRI brain map (MNI152) (Fonov et al., 2011). The solution space was limited to the cortical gray matter, including 6,239 voxels of $5 \mathrm{~mm}$ spatial resolution. The 84 commonly used Brodmann areas were chosen as regions of interests (ROIs) for topological analysis. The eLORETA tomography has been validated in several previous EEG studies (Elmer et al., 2017; Farina, Marca, Maestoso, Amoroso, \& Imperatori, 2018; Imperatori et al., 2015).

EEG source connectivity analysis was performed using eLORETA software package (http://www.uzh.ch/keyinst/ loreta.htm). Subsequently, lagged phase synchronization (LPS) method was employed for the estimation of cortical functional connectivity (FC) between all pairs of ROIs. This algorithm has been widely used to assess EEG FC (Adebimpe, Aarabi, Bourel-Ponchel, Mahmoudzadeh, \& Wallois, 2016; Farina, Marca, Maestoso, Amoroso, \& Imperatori, 2018; Hata et al., 2016), and is considered to include only physiological connectivity information (Hata et al., 2016) and be less sensitive than other techniques to physiological signals including artifacts and volume conduction effect (Pascual-Marqui et al., 2011; Stam, Nolte, \& Daffertshofer, 2010). For each subject, an $84 \times 84$ FC matrix was obtained over the all artifact-free segments in five frequency bands.

\section{Graph theoretical analysis}

In order to quantitatively investigate the topological properties of the cortical network in WM task, we constructed a series of undirected and unweighted binary matrices at different density values from the FC matrix. Density is defined as the number of existing edges divided by the maximum possible number of edges within a network. From 0.1 to 0.5 with 0.02 increments of the density values were selected to construct the brain networks. Detailed density selection principles have been elaborated in previous study (Sun, Wang \& Bo, 2019). The graph theoretical analysis was calculated using the Gretna toolbox (https://www.nitrc.org/projects/gretna).

The clustering coefficient $(\mathrm{C})$, characteristic path length (L), global efficiency (Eg) and hierarchy were calculated by the average over the whole ROIs to investigate the global topological properties. $\mathrm{C}$ is a measure of the degree of local clustering of a graph, defined as the fraction of the neighbors of a node $i$ that are also neighbors of each other. L quantifies the overall communication efficiency between any pair of nodes, which is defined as the average of the path lengths of all nodes (Watts \& Strogatz, 1998). Eg is a superior measure of integration, which is the average inverse shortest path length, measuring the global efficiency of parallel information transfer in a network (Rubinov \& Sporns, 2010). The hierarchy coefficient is used to identify the presence of a hierarchical organization in a network (Ravasz \& Barabási, 2003).

The degree and betweenness centrality (bc) of each ROI were calculated to assess the importance of individual brain regions. The degree is defined as total number of edges connected to node $i$, bc is defined as the normalized fraction of all shortest paths connecting two nodes that pass through the particular node (Rubinov \& Sporns, 2010).

\section{Statistical analysis}

The areas under the respective metric curves was used to investigate the global and local graph properties over the entire sparsity range, avoiding the bias introduced by the selection of network sparsity (Dai et al., 2017). To compare the alteration of the topological properties between the two groups, twotailed independent $t$-test was complied at the WM task. Bonferroni correction was used to address the problem of multiple comparisons. In addition, we used Pearson partial correlation coefficient to test possible correlations between the IA severity and those significantly altered properties.

\section{Ethics}

The study was conducted in accordance with the recommendations of the Declaration of Helsinki and the Liaoning Normal University Ethics Committee, and all participants had signed the informed consent.

\section{RESULTS}

\section{Behavioral results}

We compared the WM performance measured by reaction times (RT) and accuracy between the two groups. From 
Table 2. Behavioral results of the IA and the HC groups in WM task

\begin{tabular}{lccc}
\hline Group & IA $^{\text {a }}$ & HC $^{\text {a }}$ & Test values \\
\hline Reaction time (ms) & $393.39 \pm 150.44$ & $543.56 \pm 324.33$ & $t=-2.05, P=0.046$ \\
Accuracy (\%) & $76.72 \pm 13.57$ & $80.08 \pm 7.16$ & $t=-1.067, P=0.293$ \\
\hline
\end{tabular}

${ }^{a}$ Values are expressed as the mean \pm standard deviation (SD). IAT, internet addiction test.

Table 2, a clear effect on group was revealed in the RT. Compared with the HC group, the RT was significantly lower in the IA group. However, there was no significant group effect on accuracy.

\section{Global network topological characteristics}

The results of the independent $t$-test for the $\mathrm{C}, \mathrm{L}, \mathrm{Eg}$ and hierarchy indices with respect to group were reported in Table 3 for the alpha frequency band. There was no any other significant effect in other frequency bands.

We found significant topological alterations in the global network metrics between the two groups. As shown in Table 3, the mean values of $\mathrm{L}$ were significantly lower in the IA group with respect to $\mathrm{HC}$ group $(P=0.006$, significant after bonferroni correction), an opposite trend was observed for the $\operatorname{Eg}(P=0.007$, significant after bonferroni correction) and hierarchy $(P=0.022)$ indices that were significantly higher in the IA group than the HC group. There was no any significant effect on $\mathrm{C}$. The areas under the curves of the three significant global network metrics were shown in Fig. 2.

Table 3. Results on global indices in alpha frequency band

\begin{tabular}{lccrl}
\hline Global index & IA & HC & \multicolumn{1}{c}{$t$} & \multicolumn{1}{c}{$P$} \\
\hline C & $0.174 \pm 0.126$ & $0.172 \pm 0.012$ & 0.465 & 0.644 \\
L & $0.639 \pm 0.004$ & $0.643 \pm 0.005$ & -2.875 & $\mathbf{0 . 0 0 6}^{\text {a }}$ \\
Eg & $0.254 \pm 0.001$ & $0.253 \pm 0.001$ & 2.810 & $\mathbf{0 . 0 0 7}^{\text {a }}$ \\
Hierarchy & $0.083 \pm 0.034$ & $0.057 \pm 0.042$ & 2.374 & $\mathbf{0 . 0 2 2}^{*}$ \\
\hline
\end{tabular}

Significant results were highlighted in bold, $(P<0.05)$.

${ }^{a}$ Represents $P<0.0125(0.05 / 4)$, significant after bonferroni correction.

\section{Regional network characteristics}

The brain regions that showed significantly different degree and bc values between the two groups in the alpha band were shown in Table 4 and Fig. 3. Specifically, the bilateral middle frontal gyrus (MFG), bilateral superior frontal gyrus (SFG) and the right parahippocampal gyrus (paraHCG) exhibited increased degree values in the IA group than $\mathrm{HC}$ group. Compared with the HC group, the IA group indicated the bilateral anterior cingulate (AC) with decreased nodal centrality in both degree and betweenness. In addition, another brain region, left precentral gyrus (preCG) only showed decreased nodal betweenness in the IA group than the $\mathrm{HC}$ group.

Table 4. Regions showing altered nodal centralities in IA participants as compared with HC participants in alpha frequency band

\begin{tabular}{|c|c|c|}
\hline \multirow[b]{2}{*}{ Brain regions } & \multicolumn{2}{|c|}{$P$ values } \\
\hline & $\begin{array}{l}\text { Nodal } \\
\text { degree }\end{array}$ & $\begin{array}{c}\text { Nodal } \\
\text { betweenness }\end{array}$ \\
\hline \multicolumn{3}{|l|}{$I A>H C$} \\
\hline $\begin{array}{l}\text { Left middle frontal gyrus, } \\
\text { superior frontal gyrus }\end{array}$ & $0.030^{*}$ & 0.077 \\
\hline $\begin{array}{l}\text { Right middle frontal gyrus, } \\
\text { superior frontal gyrus }\end{array}$ & $0.028^{*}$ & 0.066 \\
\hline $\begin{array}{l}\text { Right parahippocampal gyrus } \\
I A<H C\end{array}$ & $0.037^{*}$ & 0.057 \\
\hline $\begin{array}{l}\text { Left anterior cingulate, cingulate } \\
\text { gyrus }\end{array}$ & $0.028^{*}$ & $0.025^{*}$ \\
\hline Left precentral gyrus & 0.105 & $0.046^{*}$ \\
\hline Right anterior cingulate & $0.008^{* *}$ & $0.016^{*}$ \\
\hline
\end{tabular}

Significant results were highlighted in bold, * represents $P<0.05$, ** represents $P<0.01$.
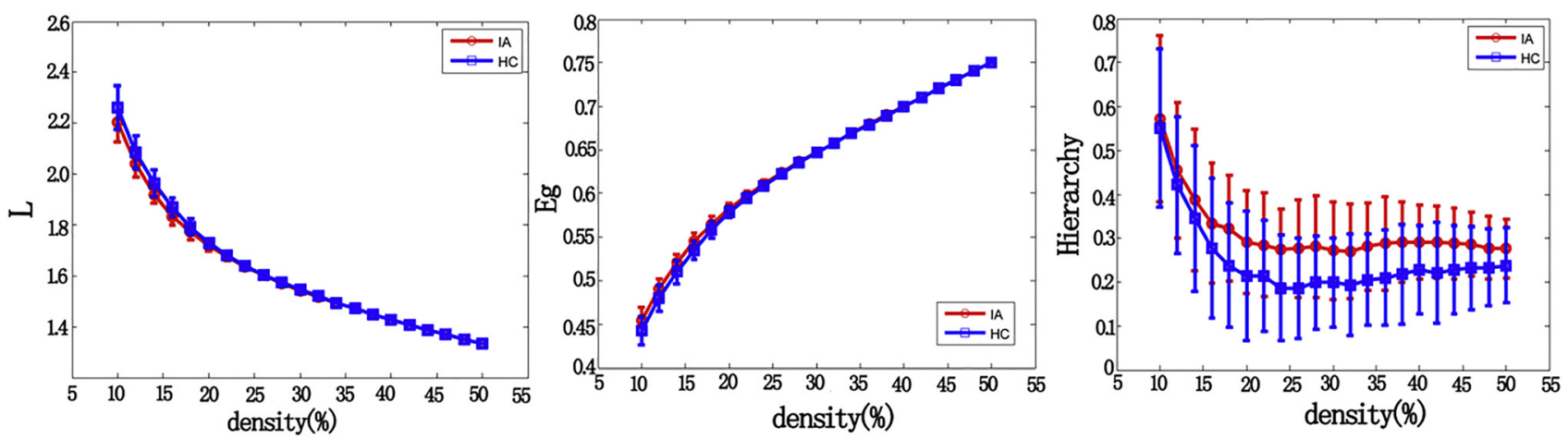

Figure 2. Average values of the global measures in the two groups in the alpha band. The areas under the respective metric curves was used to investigate the graph properties over the entire sparsity range. Red and blue present the IA and HC group, respectively 

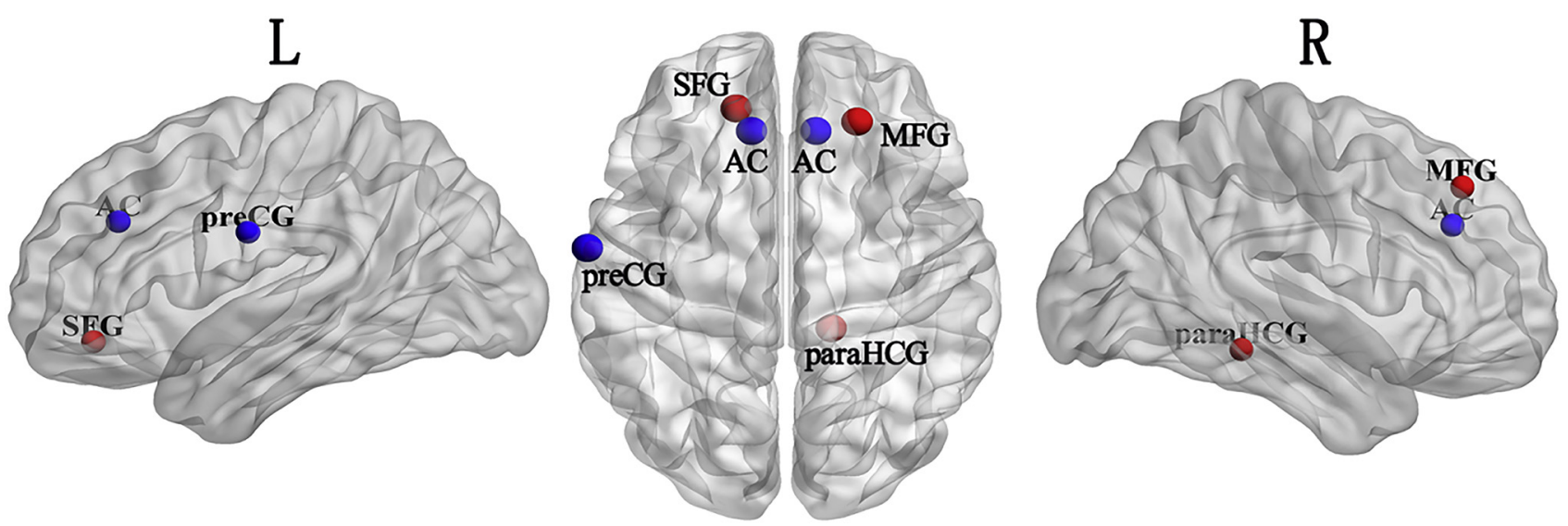

Figure 3. The source brain regions showing significantly different nodal centralities between the IA and HC groups in the alpha band. The blue node indicated IA $<\mathrm{HC}$, an opposite trend for red nodes: IA $>\mathrm{HC}$. The brain regions were overlaid on inflated surface maps with the BrainNet Viewer toolbox (Xia, Wang \& He, 2013)
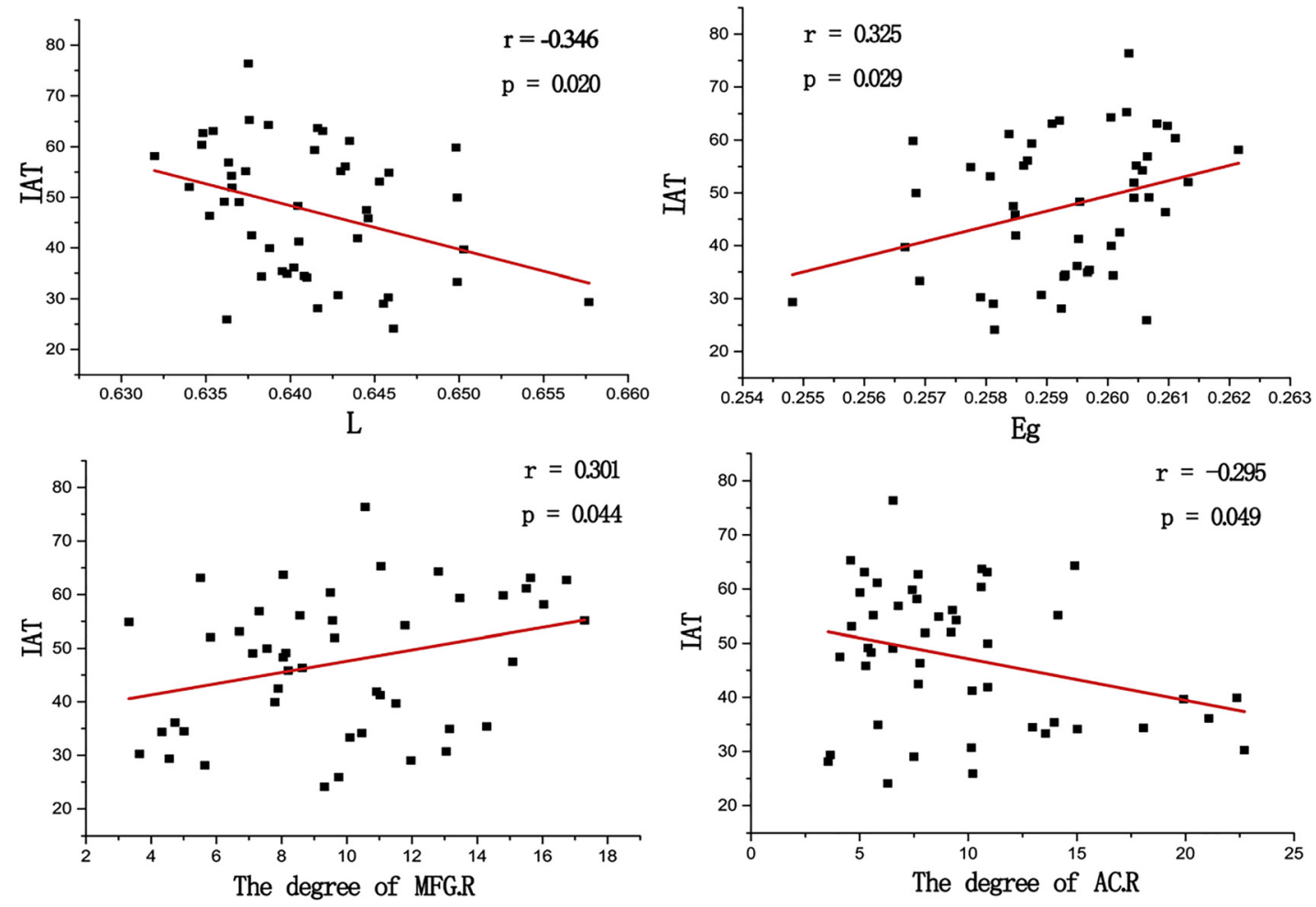

Figure 4. Scatter plots showing the partial correlations between the altered graph metrics and the IA severity. L, characteristic path length; Eg, global efficiency; MFG.R, the right middle frontal gyrus; AC.R, the right anterior cingulate. The $r$ - and $p$-values of the corresponding correlations are displayed in the figures

\section{Correlation between the IA severity and network measures}

Partial correlation was conducted between all significant global and local measures and subjects' IAT scores, including age and gender as the covariates. From Fig. 4, the $\mathrm{L}(r=-0.346, P=0.020)$ and the degree of the right AC $(r=-0.295, P=0.049)$ were revealed to possess significant negative correlation with the IA severity during the WM task. Moreover, significant positive correlations were found between the $\mathrm{Eg}(r=0.325, P=0.029)$ and the degree of right MFG ( $r=0.301, P=0.044)$ and the IA severity. No statistically significant correlation was discovered between the other graph metrics and the IA severity.

\section{DISCUSSION}

This study utilized a graph theory approach to explore complicated causality patterns derived from EEG recordings with the aim to explore the topological properties of the 
neural networks related to WM induced in visual n-back tasks performed by IA and matched HC college students. We found that (1) topological networks of IA subjects showed decreased L, and increased Eg and Hierarchy, key brain regions involving frontal (SFG, MFG and preCG.L) and limbic lobes (paraHG.R and AC) were identified; (2) the alterations of brain network topological properties of IA were correlated with the IA severity. These findings suggested that higher network efficiency and hierarchy of functional networks may be the underlying neurological mechanism of better WM process engaged in IA, better WM performance may additionally arise from alterations in specific brain regions such as frontal and limbic.

\section{The results of WM performance}

$\mathrm{WM}$ is a crucial module due to the fact that it gives the foundation for advanced cognitive functions (Dai et al., 2017). Our results showed that the IA subjects with a better performance in 2-back WM task than the HC group. The increase of memory load leads to larger demands on cognitive processes such as storage, rehearsal, temporal ordering and inhibition (Finc et al., 2017). The task with lower memory requirements can be completed automatically and effortlessly to a large extent, while to perform the more effortful 2-back task need integrating multiple brain systems to complete the complicated cognitive process. These WM load-related behavioral changes in various sampled population have been reported by recent studies (Finc et al., 2017; Heinzel et al., 2018; Huang et al., 2018).

In addition, different from some previous studies that found WM performance in the individuals of internet addicted is impaired (Laier, Schulte, \& Brand, 2013; Nie, Zhang, Chen, \& Li, 2016; Zhou, Zhou, Li \& Wang, 2014; Zhou, Zhou, \& Zhu, 2015), our observations showed that there was no significant difference in the accuracy of WM task between the IAs and the HCs, and the RT was significantly lower in the IA group than the HC group, indicating the WM capacity of internet addicted individuals is not impaired. And some previous researches also showed that addictive behaviors does not cause damage to WM ability, Yan et al. (2014) reported that the WM performance of pathological gamblers, a form of behavioral addiction, was not different from controls on the WM task. Simon et al. (2000) also found the WM capacity of the drug-addicted individuals was not significantly different from that of the control group. Several factors may explain the difference in research results. First, differences between IA participants in various studies have been observed. For example, only male/female participants were enrolled in some studies (Laier, Schulte, \& Brand, 2013; Laier, Pekal, \& Brand, 2014), while gender difference was frequently demonstrated in various studies (Jun, Sacco, Bright, \& Cunningham-Williams, 2019; Schuck, Flores, \& Fung, 2019; Zhang, Dougherty, Baum, White, \& Michael, 2018). Second, different types of IA were focused, such as cybersex addiction in internet pornography user (Laier, Pekal, \& Brand, 2014; Laier, Schulte, \& Brand, 2013) and internet gaming disorder (Du et al., 2017). In current study, the subjects may be accompanied by comprehensive IA, such as gaming, internet shopping, pornography, internet social interaction, virtual society, and obtaining information. Third, whether IA was accompanied by other psychological syndromes (e.g., depression, ADHD) should be taken seriously, and the more heavy the addiction degree, the more serious the brain damage may be.

\section{Variations in the global topological brain network}

The network with both strong global integration and high local specialization is considered to be a more economical network (Watts \& Strogatz, 1998). L is a measure of average connectivity degree or overall routing efficiency of the network, Eg represents the ability of parallel information transmission on the network (Zhu et al., 2016), the two properties are used to characterize network integration in an expanding body of studies (Baker et al., 2017; Park et al., 2018; Sun, Chen, Collinson, Bezerianos, \& Sim, 2017; Wang et al., 2018). The Eg of the cortical network of the IA participants increased significantly compared with the HC subjects, while the $\mathrm{L}$ exhibited a significant decrease. These findings indicate increased functional integration of the IA brain network and strengthened overall interaction among different brain regions when performing the WM task, which improve the overall efficiency of information transmission on the brain functional network and greatly promote the execution of the WM task. The current study in accordance with the "enhance hypothesis", it may be because the long-term use of the internet by addicts to improve the ability to refresh, convert, store, and suppress information. The repeated behaviors of internet browsing, such as contacting the network image frequently. The visual center has been stimulated persistently for a long time, turn out to be easily excited or to have a raised excitability (Liu et al., 2010).

Besides the economic and efficient small-world network, there are other two basic network topologies: regular and random. A random network is characterized by lower clustering and shorter path length at the same time, while the opposite is true for a regular network (Van Diessen, Diederen, Braun, Jansen \& Stam, 2013). In the present study, we demonstrated that the formation of an altered network associated with IA during WM task shifting toward a more random topological configuration.

Moreover, an increased hierarchy was observed in IA subjects during the 2-back task. Another graph property similar to hierarchy is module. These properties have some advantages, together with more suitable robustness, adaptivity, and evolvability of network function (Meunier, Lambiotte, \& Bullmore, 2010). Modular and hierarchical organization is described as a subset of highly inter-connected nodes surprisingly moderately linked to nodes in different modules (Finc et al., 2017; Iordan et al., 2018; Li et al., 2018). An increased hierarchy in IA subjects may indicate relatively more short distance connections. Therefore, taking into account the observed alterations in the global properties of IA participants, we speculate that the 
better WM performance of the IA group might be associated with the strengthened global integration of brain regions functionally related during the WM task.

\section{Alterations in the importance of individual brain regions}

It is worth noting that the alterations of brain regional features are increasingly considered to emphasize the neurobiological basis of information transmission and integration (Olaf, Honey, Rolf, \& Marcus, 2007). The present study confirmed our hypothesis and found that the altered WM performance in IA subjects was associated with nodal alterations predominantly in frontal and limbic cortices. Specifically, there were increased nodal degree in bilateral MFG, bilateral SFG and the right ParaHG, the bilateral AC with decreased nodal centrality in both degree and betweenness, the left preCG only showed decreased nodal betweenness in the IA group than the HC group. Conceptually, higher regional degree and bc indicate a more central or important role of the node in the functional network. Reduced centrality in bilateral AC and the left preCG indicated decreased importance within the IA brain network in the WM task, and increased importance of bilateral MFG, bilateral SFG and hippocampus lobes may compensate this unbalance.

Imaging studies have pointed out that frontal has been consistently determined to be related to WM demand and to be a dependable index of variations in the memory load of WM tasks (Grunwald, Weiss, Mueller, \& Rall, 2014; Hsieh \& Ranganath, 2014; Niendam et al., 2012). The executive control processe is located in the prefrontal cortex (PFC); particularly activations of the PFC has been observed in tasks that require executive control (Bunge, Klingberg, Jacobsen \& Gabrieli, 2000; Osaka et al., 2003, 2004), and decreased AC cortex blood flow was discovered during cognitive tasks that demand attention (deactivation), including visual spatial and WM tasks (Corbetta, Miezin, Dobmeyer, Shulman \& Petersen, 1991; Rose, Simonotto \& Ebmeier, 2006). To our knowledge, MFG and SFG as a part of prefrontal cortex involved in executive functions (Yuan \& Raz, 2014). WM is an executive function involving a series of intricate courses such as encoding, executive maintenance and retrieval (Toppi et al., 2018). Structural and functional prefrontal abnormalities were widely reported in individuals with IA (Choi et al., 2017; Pan et al., 2018; Park et al., 2016; Shakir et al., 2015), drug addiction (Bolla, Eldreth, Matochik, \& Cadet, 2005; Bolla et al., 2004) and alcohol addiction (Ge et al., 2017; Han et al., 2015a).

The ParaHG region is a part of the limbic system, which communicates with the hippocampus to encode, maintain and retrieve information (Surhone, Tennoe, \& Henssonow, 2012), and is believed to contribute to the formation and maintenance of information in working memory (Aguirre, Detre, Alsop, \& D’Esposito, 1996; Engle \& Kane, 2004; Luck et al., 2010). The ParaHG region has the ability to maintain stimulus representations for a long time, and in doing so, the simultaneous stimuli can be combined into relevant representations in memory, which is important for maintaining and retrieving the information (Smith \& Milner, 1989). Alteration in this region can be revealed in considerable addiction-related studies such as smokers (Hanlon et al., 2016), internet addicts (Liu et al., 2010; Wang et al., 2016; Yuan et al., 2011, 2013). Thus, the relative enhancement in ParaHG region importance in our study indicated an increasing effort in memory recollection of meaningful experience in IA subjects in order to complete the N-back WM task. In a word, the alteration of the importance of frontal and ParaHG regions may imply changes in the WM performance of IA subjects.

\section{Correlation between global topological properties and WM performance}

The observation that WM-induced topological changes correlated with IA severity adds to an existing body of literature showing that performance stability is closely linked to neurophysiology function. Specifically, we found a negative relationship between the IA severity and L and a positive relationship between the IA severity and Eg. Since the $\mathrm{L}$ and $\mathrm{Eg}$ are associated with the global integration, this finding further corroborates the more integrative functional brain network of IA during the WM task. Furthermore, the nodal network metrics were correlated with IA severity. We observed a positive relationship of IA severity with degree of the right MFG, and a negative relationship of IA severity with the degree of right AC. Altered neural activity of these regions in IA group has been demonstrated in the previous studies (Ding et al., 2014; Dong, Devito, Du \& Cui, 2012). These findings indicate the important role of brain topological changes derived from graph theory in understanding the neural mechanism of IA and will help determine affected regions related to $\mathrm{WM}$ in $\mathrm{IA}$.

\section{Limitations and future directions}

Several limitations to this study should be mentioned. First, in order to minimize potential effects of the EEG reference on signals, a number of different references have been proposed, such as linked mastoids (Dan, 2018), average reference (Zheng, Qi, Li, Zhang, \& Yu, 2018) and zero reference (Dong et al., 2017). With some suggestiones (Dong et al., 2017; Xu et al., 2014), zero reference was adopted in current study. Until now there is no gold standard; therefore, future research should pay more attention to explore a more accurate reference model. Second, each ROI was determined by predefinition rather than by adaptive parcellation, we only used the Brodmann atlas including 84 regions to analyze the topological organization of brain functional connectomes. However, network properties are sensitive to nodal definition based on parcellation strategies and spatial scales (Wang et al., 2011). More robust parcellation scale and test-retest reliability atlas need to be clearly studied in the future work. Third, the current study is the crosssectional design may reflect baseline differences in cognitive abilities and not fully differentiate the effects of IA in college 
students, therefore we are cautious in interpreting the study results. Future studies may benefit from longitudinal assessments of these effects. Fourth, what we focused is a general IA in current study. In fact, different internet use behaviors may have different effects on WM (Du et al., 2017; Laier, Pekal, \& Brand, 2014; Laier, Schulte, \& Brand, 2013), or even different types of the same application (e.g. different types of games) may also have different effects. Therefore, this also suggests that we can select different types of internet addicts in the future to explore the differences in the characteristics and brain mechanisms of verbal and visual WM. Finally, the relatively small sample size may limit the statistical power, our results should be confirmed by studies with a larger sample size.

\section{CONCLUSIONS}

In conclusion, graph theoretical analysis of the functional brain networks of the IA participants during the WM task was performed in this study, which provides the opportunity to investigate the broader network aberrations as well as altered individual regions in IA. We found that there were significant alterations in topological properties both globally and regionally in IA, which were also correlated with IA severity. These findings provide evidence to support the notion that altered topological configuration may underline improved WM function observed in IA and highlight the potential of complex network measures as neural biomarkers for behavioral presentation of IA.

Funding sources: This work was supported by the Educational Department in Liaoning Province (WJ2019015) and Humanities and Social Sciences Project of MOE (Ministry of Education in China) (17YJA190011).

Authors' contribution: HW and YS conceived and initiated the study in this paper. HW conducted the experiment, FL and YL analyzed the data and checked the reference. HW and YS interpreted the results and drafted the manuscript. All authors reviewed the manuscript and approved the final version for the publication.

Conflict of interest: We declare that we have no conflict of interest.

\section{REFERENCES}

Adebimpe, A., Aarabi, A., Bourel-Ponchel, E., Mahmoudzadeh, M., \& Wallois, F. (2016). EEG resting state functional connectivity analysis in children with benign epilepsy with centrotemporal spikes. Frontiers in Neuroscience, 10, 143. http://doi.org/10. 3389/fnins.2016.00143.

Aguirre, G. K., Detre, J. A., Alsop, D. C., \& D’Esposito, M. (1996). The parahippocampus subserves topographical learning in man. Cerebral Cortex, 6(6), 823-829. https://doi.org/10.1093/ cercor/6.6.823.

Baddeley, A. (2012). Working memory: Theories, models, and controversies. Annual Review of Psychology, 63(1), 1-29. https://doi.org/10.1146/annurev-psych-120710-100422.

Baker, L. M., Cooley, S. A., Cabeen, R. P., Laidlaw, D. H., Joska, J. A., Hoare, J., et al. (2017). Topological organization of wholebrain white matter in HIV infection. Brain Connectivity, 7(2), 115-122. https://doi.org/10.1089/brain.2016.0457.

Bassett, D. S., \& Bullmore, E. (2006). Small-world brain networks. The Neuroscientist, 12(6), 512-523. https://doi.org/10.1177/ 1073858406293182.

Bavelier, D., Green, C. S., Han, D. H., Renshaw, P. F., Merzenich, M. M., \& Gentile, D. A. (2011). Brains on video games. Nature Reviews Neuroscience, 12(12), 763-768. https://doi.org/10. 1038/nrn3135.

Bilek, E., Schäfer, A., Ochs, E., Esslinger, C., Zangl, M., Plichta, M. M., et al. (2013). Application of high-frequency repetitive transcranial magnetic stimulation to the dlpfc alters human prefrontal-hippocampal functional interaction. Journal of Neuroscience, 33(16), 7050-7056. https://doi.org/10.1523/ JNEUROSCI.3081-12.2013.

Bolla, K. I., Eldreth, D. A., Matochik, J. A., \& Cadet, J. L. (2005). Neural substrates of faulty decision-making in abstinent marijuana users. Neuroimage, 26(2), 480-492. https://doi.org/10. 1016/j.neuroimage.2005.02.012.

Bolla, K., Ernst, M., Kiehl, K., Mouratidis, M., Eldreth, D., Contoreggi, C., et al. (2004). Prefrontal cortical dysfunction in abstinent cocaine abusers. Journal of Neuropsychiatry and Clinical Neurosciences, 16(4), 456-464. https://doi.org/10.1176/ jnp.16.4.456.

Brand, M., Wegmann, E., Stark, R., Müller, A., Wölfling, K., Robbins, T. W., et al. (2019). The Interaction of Person-AffectCognition-Execution (I-PACE) model for addictive behaviors: Update, generalization to addictive behaviors beyond Internetuse disorders, and specification of the process character of addictive behaviors. Neuroscience \& Biobehavioral Reviews, 104, 1-10. https://doi.org/10.1016/j.neubiorev.2019.06.032.

Brier, M. R., Thomas, J. B., Fagan, A. M., Hassenstab, J., Holtzman, D. M., Benzinger, T. L., et al. (2014). Functional connectivity and graph theory in preclinical alzheimer's disease. Neurobiology of Aging, 35(4), 757-768. https://doi.org/10.1016/j.neurobiolaging. 2013.10.081.

Brooks, S. J., Funk, S. G., Young, S. Y., \& Schiöth, H. B. (2017). The role of working memory for cognitive control in anorexia nervosa versus substance use disorder. Frontiers in Psychology, 8, 1651. https://doi.org/10.3389/fpsyg.2017.01651.

Bunge, S. A., Klingberg, T., Jacobsen, R. B., \& Gabrieli, J. D. E. (2000). A resource model of the neural basis of executive working memory. Proceedings of the National Academy of Sciences, 97(7), 3573-3578. https://doi.org/10.1073/pnas.97.7.3573.

Cao, H., Plichta, M. M., Schäfer, A., Haddad, L., Grimm, O., Schneider, M., et al. (2014). Test-retest reliability of fMRIbased graph theoretical properties during working memory, emotion processing, and resting state. Neuroimage, 84, 888900. https://doi.org/10.1016/j.neuroimage.2013.09.013.

Chen, C. Y., Huang, M. F., Yen, J. Y., Chen, C. S., Liu, G. C., Yen, C. F., et al. (2015). Brain correlates of response inhibition in 
internet gaming disorder. Psychiatry and Clinical Neurosciences, 69(4), 201-209. https://doi.org/10.1111/pcn.12224.

Choi, J., Cho, H., Kim, J. Y., Jung, D. J., Ahn, K. J., Kang, H. B., et al. (2017). Structural alterations in the prefrontal cortex mediate the relationship between internet gaming disorder and depressed mood. Scientific Reports, 7(1), 1245. https://doi.org/ 10.1038/s41598-017-01275-5.

Choi, J. S., Park, S. M., Roh, M. S., Lee, J. Y., Park, C. B., Hwang, J. Y., et al. (2014). Dysfunctional inhibitory control and impulsivity in internet addiction. Psychiatry Research, 215(2), 424428. https://doi.org/10.1016/j.psychres.2013.12.001.

Corbetta, M., Miezin, F. M., Dobmeyer, S., Shulman, G. L., \& Petersen, S. E. (1991). Selective and divided attention during visual discriminations of shape, color, and speed: Functional anatomy by positron emission tomography. Journal of Neuroscience, 11(8), 2383-2402. https://doi.org/10.1523/JNEUROSCI.11-08-02383.1991.

Dai, Z., De Souza, J., Lim, J., Ho, P. M., Chen, Y., Li, J., et al. (2017). EEG cortical connectivity analysis of working memory reveals topological reorganization in theta and alpha bands. Frontiers in Human Neuroscience, 11, 237. https://doi.org/10.3389/ fnhum.2017.00237.

Dan, W. (2018). Hearing the sound in the brain: Influences of different EEG references. Frontiers in Neuroscience, 12, 148. https://doi.org/10.3389/fnins.2018.00148.

Ding, W. N., Sun, J. H., Sun, Y. W., Chen, X., Zhou, Y., Zhuang, Z. G., et al. (2014). Trait impulsivity and impaired prefrontal impulse inhibition function in adolescents with internet gaming addiction revealed by a go/no-go fMRI study. Behavioral and Brain Functions, 10(1), 20. https://doi.org/10.1186/1744-9081-10-20.

Dong, G., Devito, E. E., Du, X., \& Cui, Z. (2012). Impaired inhibitory control in 'internet addiction disorder': A functional magnetic resonance imaging study. Psychiatry Research: Neuroimaging, 203(2-3), 153-158. https://doi.org/10.1016/j. pscychresns.2012.02.001.

Dong, L., Li, F., Liu, Q., Wen, X., Lai, Y., Xu, P., et al. (2017). Matlab toolboxes for reference electrode standardization technique (REST) of scalp EEG. Frontiers in Neuroscience, 11, 601. https://doi.org/10.3389/fnins.2017.00601.

Du, X., Yang, Y., Gao, P., Qi, X., Du, G., Zhang, Y., et al. (2017). Compensatory increase of functional connectivity density in adolescents with internet gaming disorder. Brain Imaging and Behavior, 11(6), 1901-1909. https://doi.org/10.1007/s11682016-9655-X.

Elmer, S., Kühnis, J., Rauch, P., Abolfazl Valizadeh, S., \& Jäncke, L. (2017). Functional connectivity in the dorsal stream and between bilateral auditory-related cortical areas differentially contribute to speech decoding depending on spectro-temporal signal integrity and performance. Neuropsychologia, 106, 398406. https://doi.org/10.1016/j.neuropsychologia.2017.

Engle, R. W., \& Kane, M. J. (2004). Executive attention, working memory capacity, and a two-factor theory of cognitive control. Psychology of Learning and Motivation, 44(03), 145-199. https://doi.org/10.1016/S0079-7421(03)44005-X.

Ewald, A., Marzetti, L., Zappasodi, F., Meinecke, F. C., \& Nolte, G. (2012). Estimating true brain connectivity from EEG/MEG data invariant to linear and static transformations in sensor space. Neuroimage, 60(1), 476-488. https://doi.org/10.1016/j. neuroimage.2011.11.084.
Farina, B., Marca, G. D., Maestoso, G., Amoroso, N., \& Imperatori, C. (2018). The association among default mode network functional connectivity, mentalization, and psychopathology in a nonclinical sample: An eLORETA study. Psychopathology, 51(1), 16-23. https://doi.org/10.1159/000485517.

Finc, K., Bonna, K., Lewandowska, M., Wolak, T., Nikadon, J., Dreszer, J., et al. (2017). Transition of the functional brain network related to increasing cognitive demands. Human Brain Mapping, 38(7), 3659-3674. https://doi.org/10.1002/hbm. 23621.

Fonov, V., Evans, A. C., Botteron, K., Almli, C. R., McKinstry, R. C., \& Collins, L. (2011). Unbiased average age-appropriate atlases for pediatric studies. Neuroimage, 54, 313-327. https://doi.org/ 10.1016/j.neuroimage.2010.07.033.

Franciotti, R., Falasca, N. W., Arnaldi, D., Famà, F., Babiloni, C., Onofrj, M., et al. (2019). Cortical network topology in prodromal and mild dementia due to Alzheime's disease: Graph theory applied to resting state EEG. Brain Topography, 32(1), 127-141. https://doi.org/10.1007/s10548-018-0674-3.

Ge, X., Sun, Y., Han, X., Wang, Y., Ding, W., Cao, M., et al. (2017). Difference in the functional connectivity of the dorsolateral prefrontal cortex between smokers with nicotine dependence and individuals with internet gaming disorder. BMC Neuroscience, 18(1), 54. https://doi.org/10.1186/s12868-017-0375-y.

Gomez-Pilar, J., de Luis-García, R., Lubeiro, A., de la Red, H., Poza, J., Núñez, P., et al. (2018). Relations between structural and EEG-based graph metrics in healthy controls and schizophrenia patients. Human Brain Mapping, 39(8), 3152-3165. https://doi. org/10.1002/hbm.24066.

Grunwald, M., Weiss, T., Mueller, S., \& Rall, L. (2014). EEG changes caused by spontaneous facial self-touch may represent emotion regulating processes and working memory maintenance. Brain Research, 1557, 111-126. https://doi.org/10.1016/j. brainres.2014.02.002.

Han, D. H., Bolo, N., Daniels, M. A., Arenella, L., Lyoo, I. K. \& Renshaw, P. F. (2011). Brain activity and desire for internet video game play. Comprehensive Psychiatry, 52(1), 88-95. https://doi.org/10.1016/j.comppsych.2010.04.004.

Han, J. W., Han, D. H., Bolo, N., Kim, B. A., Kim, B. N. \& Renshaw, P. F. (2015a). Differences in functional connectivity between alcohol dependence and internet gaming disorder. Addictive Behaviors, 41, 12-19. https://doi.org/10.1016/j.addbeh.2014.09. 006.

Han, D. H., Kim, S. M., Bae, S., Renshaw, P. F., \& Anderson, J. S. (2015b). Brain connectivity and psychiatric comorbidity in adolescents with internet gaming disorder. Addiction Biology, 22(3), 802-812. https://doi.org/10.1111/adb.12347.

Hanlon, C. A., Owens, M. M., Joseph, J. E., Zhu, X., George, M. S., Brady, K. T., et al. (2016). Lower subcortical gray matter volume in both younger smokers and established smokers relative to non-smokers. Addiction Biology, 21(1), 185-195. https://doi. org/10.1111/adb.12171.

Hata, M., Kazui, H., Tanaka, T., Ishii, R., Canuet, L., PascualMarqui, R. D., et al. (2016). Functional connectivity assessed by resting state EEG correlates with cognitive decline of alzheimer's disease - an eLORETA study. Clinical Neurophysiology, 127(2), 1269-1278. https://doi.org/10.1016/j.clinph.2015. 10.030 . 
Heinzel, S., Kaufmann, C., Grützmann, R., Hummel, R., Klawohn, J., Riesel, A., et al. (2018). Neural correlates of working memory deficits and associations to response inhibition in obsessive compulsive disorder. Neuroimage: Clinical, 17, 426-434. https://doi.org/10.1016/j.nicl.2017.10.039.

Hong, J. S., Sun, M. K., Bae, S., \& Han, D. H. (2018). Impulsive internet game play is associated with increased functional connectivity between the default mode and salience networks in depressed patients with short allele of serotonin transporter gene. Frontiers in Psychiatry, 9, 125. https://doi.org/10.3389/ fpsyt.2018.00125.

Hsieh, L. T., \& Ranganath, C. (2014). Frontal midline theta oscillations during working memory maintenance and episodic encoding and retrieval. Neuroimage, 85, 721-729. https://doi. org/10.1016/j.neuroimage.2013.08.003.

Huang, H., Nguyen, P. T., Schwab, N. A., Tanner, J. J., Price, C. C., \& Ding, M. (2017). Mapping dorsal and ventral caudate in older adults: Method and validation. Frontiers in Aging Neuroscience, 9, 91. https://doi.org/10.3389/fnagi.2017. 00091.

Huang, M. X., Nichols, S., Robb-Swan, A., Angeles-Quinto, A., Harrington, D. L., Drake, A., et al. (2018). MEG working memory n-back task reveals functional deficits in combatrelated mild traumatic brain injury. Cerebral Cortex, 29(5), 1953-1968. https://doi.org/10.1093/cercor/bhy075.

Imperatori, C., Fabbricatore, M., Innamorati, M., Farina, B., Quintiliani, M. I., Lamis, D. A., et al. (2015). Modification of EEG functional connectivity and EEG power spectra in overweight and obese patients with food addiction: An eLORETA study. Brain Imaging and Behavior, 9(4), 703-716. https://doi. org/10.1007/s11682-014-9324-x.

Iordan, A. D., Cooke, K. A., Moored, K. D., Katz, B., Buschkuehl, M., Jaeggi, S. M., et al. (2018). Aging and network properties: Stability over time and links with learning during working memory training. Frontiers in Aging Neuroscience, 9, 419. https://doi.org/10.3389/fnagi.2017.00419.

Jasper, L. E. (2016). Working memory and long-term Abstinence from substance use. Doctor of Psychology (PsyD). 190. https:// digitalcommons.georgefox.edu/psyd/190.

Jun, H. J., Sacco, P., Bright, C., \& Cunningham-Williams, R. M. (2019). Gender differences in the relationship between depression, antisocial behavior, alcohol use, and gambling during emerging adulthood. International Journal of Mental Health and Addiction, 17, 1-12. https://doi.org/10.1007/ s11469-018-0048-9.

Jung, T. P., Makeig, S., Westerfield, M., Townsend, J., Courchesne, E., \& Sejnowski, T. J. (2001). Analysis and visualization of single-trial event-related potentials. Human Brain Mapping, 14(3), 166-185. https://doi.org/10.1002/hbm.1050.

Kim, J. W., Kim, S. Y., Choi, J. W., Kim, K. M., Nam, S. H., Min, K. J., et al. (2017). Differences in resting-state quantitative electroencephalography patter.ns in attention deficit/hyperactivity disorder with or without comorbid symptoms. Clinical Psychopharmacology \& Neuroscience, 15(2), 138-145. https://doi. org/10.9758/cpn.2017.15.2.138.

Kraut, R., Kiesler, S., Boneva, B., Cummings, J., Helgeson, V., \& Crawford, A. (2002). Internet paradox revisited. Journal of
Social Issues, 58(1), 49-74. https://doi.org/10.1111/1540-4560. 00248.

Kraut, R., Patterson, M., Lundmark, V., kiesler, S., Mukopadhyay, T., \& Scherlis, W. (1998). Internet paradox: A social technology that reduces social involvement and psychological well-being? American Psychologist, 53(9), 1017-1031. https://doi.org/10. 1037//0003-066X.53.9.1017.

Ladouceur, C. D., Diwadkar, V. A., White, R., Bass, J., Birmaher, B., Axelson, D. A., et al. (2013). Fronto-limbic function in unaffected offspring at familial risk for bipolar disorder during an emotional working memory paradigm. Developmental Cognitive Neuroscience, 5, 185-196. https://doi.org/10.1016/j.dcn. 2013.03.004.

Laier, C., Pekal, J., \& Brand, M. (2014). Cybersex addiction in heterosexual female users of internet pornography can be explained by gratification hypothesis. Cyberpsychology, Behavior, and Social Networking, 17(8), 505-511. https://doi. org/10.1089/cyber.2013.0396.

Laier, C., Schulte, F. P., \& Brand, M. (2013). Pornographic picture processing interferes with working memory performance. The Journal of Sex Research, 50(7), 642-652. https://doi.org/10. 1080/00224499.2012.716873.

Lee, J., Hwang, J. Y., Park, S. M., Jung, H. Y., Choi, S. W., Lee, J. Y., et al. (2014). Differential resting-state EEG patterns associated with comorbid depression in internet addiction. Progress in Neuropsychopharmacology \& Biological Psychiatry, 50(4), 21-26. https://doi.org/10.1016/j.pnpbp.2013.11. 016.

Lee, M., Min, A., Hwang, Y. H., Dong, Y. K., Han, B. S., \& Seo, H. S. (2017). Structural brain network abnormalities in subjects with internet addiction. Journal of Mechanics in Medicine and Biology, 17(7), 1740031. https://doi.org/10.1142/ S0219519417400310.

Li, Z., Chen, R., Guan, M., Wang, E., Qian, T., Zhao, C., et al. (2018). Disrupted brain network topology in chronic insomnia disorder: A resting-state fMRI study. Neuroimage: Clinical, 18, 178-185. https://doi.org/10.1016/j.nicl.2018.01.012.

Liang, X., Zou, Q., He, Y., \& Yang, Y. (2016). Topologically reorganized connectivity architecture of default-mode, executivecontrol, and salience networks across working memory task loads. Cerebral Cortex, 26(4), 1501-1511. https://doi.org/10. 1093/cercor/bhu316.

Liu, J., Gao, X. P., Osunde, I., Li, X., \& Li, L. J. (2010). Increased regional homogeneity in internet addiction disorder: A resting state functional magnetic resonance imaging study. Chinese Medical Journal, 123(14), 1904-1908. https://doi.org/10.3760/ cma.j.issn.0366-6999.2010.14.014.

Luck, D., Danion, J. M., Marrer, C., Pham, B. T., Gounot, D., \& Foucher, J. (2010). The right parahippocampal gyrus contributes to the formation and maintenance of bound information in working memory. Brain and Cognition, 72, 255-263. https:// doi.org/10.1016/j.bandc.2009.09.009.

Mantini, D., Corbetta, M., Perrucci, M. G., Romani, G. L., \& Del Gratta, C. (2009). Large-scale brain networks account for sustained and transient activity during target detection. NeuroImage, 44(1), 265-274. https://doi.org/10.1016/j.neuroimage. 2008.08.019. 
Meng, Y., Deng, W., Wang, H., Guo, W., Li, T. (2015). The prefrontal dysfunction in individuals with internet gaming disorder: A meta-analysis of functional magnetic resonance imaging studies. Addiction Biology 20, 799-808. https://doi.org/10.1111/ adb.12154.

Meunier, D., Lambiotte, R., \& Bullmore, E. T. (2010). Modular and hierarchically modular organization of brain networks. Frontiers in Neuroscience, 4(4), 200. https://doi.org/10.3389/fnins. 2010.00200 .

Nie, J., Zhang, W., Chen, J., \& Li, W. (2016). Impaired inhibition and working memory in response to internet-related words among adolescents with internet addiction: A comparison with attention-deficit/hyperactivity disorder. Psychiatry Research, 236, 28-34. https://doi.org/10.1016/j.psychres.2016.01.004.

Niendam, T. A., Laird, A. R., Ray, K. L., Dean, Y. M., Glahn, D. C., \& Carter, C. S. (2012). Meta-analytic evidence for a superordinate cognitive control network subserving diverse executive functions. Cognitive, Affective, \& Behavioral Neuroscience, 12(2), 241-268. https://doi.org/10.3758/s13415-011-0083-5.

Olaf, S., Honey, C. J., Rolf, K., \& Marcus, K. (2007). Identification and classification of hubs in brain networks. PloS One, 2(10), e1049. https://doi.org/10.1371/journal.pone.0001049.

Oldfield, R. C. (1971). The assessment and analysis of handedness: The edinburgh inventory. Neuropsychologia, 9(1), 97-113. https://doi.org/10.1016/0028-3932(71)90067-4.

Osaka, M., Osaka, N., Kondo, H., Morishita, M., Fukuyama, H., Aso, T., et al. (2003). The neural basis of individual differences in working memory capacity: An fMRI study. Neuroimage, 18(3), 789-797. https://doi.org/10.1016/S1053-8119(02)000320.

Osaka, N., Osaka, M., Kondo, H., Morishita, M., Fukuyama, H., \& Shibasaki, H. (2004). The neural basis of executive function in working memory: An fMRI study based on individual differences. Neuroimage, 21(2), 623-631. https://doi.org/10.1016/j. neuroimage.2003.09.069.

Pan, N., Yang, Y., Du, X., Qi, X., Du, G., Zhang, Y., et al. (2018). Brain structures associated with internet addiction tendency in adolescent online game players. Frontiers in Psychiatry, 9, 67. https://doi.org/10.3389/fpsyt.2018.00067.

Park, S. Y., Kim, S. M., Roh, S., Soh, M. A., Lee, S. H., Kim, H., et al. (2016). The effects of a virtual reality treatment program for online gaming addiction. Comput Methods and Programs in Biomedicine, 129, 99-108. https://doi.org/10.1016/j.cmpb.2016. 01.015.

Park, S. M., Lee, J. Y., Kim, Y. J., Lee, J. Y., Jung, H. Y., Sohn, B. K., et al. (2017). Neural connectivity in internet gaming disorder and alcohol use disorder: A resting-state EEG coherence study. Scientific Reports, 7(1), 1333. https://doi.org/10.1038/s41598017-01419-7.

Park, K. M., Lee, B. I., Shin, K. J., Ha, S. Y., Park, J., Kim, T. H., et al. (2018). Progressive topological disorganization of brain network in focal epilepsy. Acta Neurologica Scandinavica, 137(4), 425-431. https://doi.org/10.1111/ane.12899.

Pascual-Marqui, R. D., Lehmann, D., Koukkou, M., Kochi, K., Anderer, P., Saletu, B., et al. (2011). Assessing interactions in the brain with exact low-resolution electromagnetic tomography. Philosophical Transactions of the Royal Society A:
Mathematical, Physical \& Engineering Sciences, 369(1952), 3768-3784. https://doi.org/10.1098/rsta.2011.0081.

Pezawas, L., Meyer-Lindenberg, A., Drabant, E. M., Verchinski, B. A., Munoz, K. E., Kolachana, B. S., et al. (2005). 5-HTTLPR polymorphism impacts human cingulate-amygdala interactions: A genetic susceptibility mechanism for depression. Nature Neuroscience, 8(6), 828-834. https://doi.org/10.1038/ nn1463.

Ravasz, E., \& Barabási, A. L. (2003). Hierarchical organization in complex networks. Physical Review E, 67(2), 026112. https:// doi.org/10.1103/PhysRevE.67.026112.

Rose, E. J., Simonotto, E., \& Ebmeier, K. P. (2006). Limbic overactivity in depression during preserved performance on the nback task. Neuroimage, 29(1), 203-215. https://doi.org/10.1016/ j.neuroimage.2005.07.002.

Rubinov, M., \& Sporns, O. (2010). Complex network measures of brain connectivity: Uses and interpretations. Neuroimage, 52(3), 1059-1069. https://doi.org/10.1016/j.neuroimage.2009.10.00.

Scheeringa, R., Petersson, K. M., Oostenveld, R., Norris, D. G., Hagoort, P., \& Bastiaansen, M. C. (2009). Trial-by-trial coupling between EEG and BOLD identifies networks related to alpha and theta EEG power increases during working memory maintenance. Neuroimage, 44(3), 1224-1238. https://doi.org/ 10.1016/j.neuroimage.2008.08.041.

Schuck, R. K., Flores, R. E., \& Fung, L. K. (2019). Brief report: Sex/ gender differences in symptomology and camouflaging in adults with autism spectrum disorder. Journal of Autism and Developmental Disorders, 49(6), 2597-2604. https://doi.org/10. 1007/s10803-019-03998-y.

Shakir, T. M., Zhang, M., Niu, C., Mao, C., Niu, X., Wang, H., et al. (2015). The alteration of gray matter volume and cognitive control in adolescents with internet gaming disorder. Frontiers in Behavioral Neuroscience, 9, 64. https://doi.org/10.3389/ fnbeh.2015.00064.

Simon, S. L., Domier, C., Carnell, J., Brethen, P., Rawson, R., \& Ling, W. (2000). Cognitive impairment in individuals currently using methamphetamine. American Journal on Addictions, 9(3), 222-231. https://doi.org/10.1080/10550490050148053.

Smith, M. L., \& Milner, B. (1989). Right hippocampal impairment in the recall of spatial location: Encoding deficit or rapid forgetting?. Neuropsychologia, 27(1), 71-81. https://doi.org/10. 1016/0028-3932(89)90091-2.

Spada, M. M. (2014). An overview of problematic internet use. Addictive Behaviors, 39(1), 3-6. https://doi.org/10.1016/j. addbeh.2013.09.007.

Stam, C. J., Nolte, G., \& Daffertshofer, A. (2010). Phase lag index: Assessment of functional connectivity from multi channel EEG and MEG with diminished bias from common sources. Human Brain Mapping, 28(11), 1178-1193. https://doi.org/10.1002/ hbm.20346.

Sun, Y., Chen, Y., Collinson, S. L., Bezerianos, A., \& Sim, K. (2017). Reduced hemispheric asymmetry of brain anatomical networks is linked to schizophrenia: A connectome study. Cerebral Cortex, 27(1), 602-615. https://doi.org/10.1093/cercor/bhv255.

Sun, Y., Taya, F., Chen, Y., Martinez, I. D., Thakor, N., \& Bezerianos, A. (2014). Topological changes of the effective connectivity during the working memory training. Annual 
International Conference of the Engineering in Medicine and Biology Society, 36, 6242-6245. https://doi.org/10.1109/EMBC. 2014.6945055.

Sun, Y., Wang, H. X., \& Bo, S. Y. (2019).Altered topological connectivity of internet addiction in resting-state EEG through network analysis. Addictive Behaviors,95, 49-57. https://doi. org/10.1016/j.addbeh.2019.02.015.

Surhone, L. M., Tennoe, M. T., \& Henssonow, S. F. (2012). Parahippocampal gyrus. Springer US. https://doi.org/10.1007/9781-4419-1428-6_2315.

Toppi, J., Astolfi, L., Risetti, M., Anzolin, A., Kober, S. E., Wood, G., et al. (2018). Different topological properties of EEG-derived networks describe working memory phases as revealed by graph theoretical analysis. Frontiers in Human Neuroscience, 11, 637. https://doi.org/10.3389/fnhum.2017.00637.

Van Diessen, E., Diederen, S. J. H., Braun, K. P. J., Jansen, F. E. \& Stam, C. J. (2013). Functional and structural brain networks in epilepsy: What have we learned?. Epilepsia, 54(11), 1855-1865. https://doi.org/10.1111/epi.12350.

Vecchio, F., Miraglia, F., Gorgoni, M., Ferrara, M., Iberite, F., Bramanti, P., et al. (2017). Cortical connectivity modulation during sleep onset: A study via graph theory on EEG data. Human Brain Mapping, 38(11), 5456-5464. https://doi.org/10. 1002/hbm.23736.

Vecchio, F., Miraglia, F., Marra, C., Quaranta, D., Vita, M. G., Bramanti, P., et al. (2014). Human brain networks in cognitive decline: A graph theoretical analysis of cortical connectivity from EEG data. Journal of Alzheimer's Disease, 41(1), 113-127. https://doi.org/10.3233/jad-132087.

Vecchio, F., Miraglia, F., Quaranta, D., Granata, G., Romanello, R., Marra, C., et al. (2016). Cortical connectivity and memory performance in cognitive decline: A study via graph theory from EEG data. Neuroscience, 316, 143-150. https://doi.org/10. 1016/j.neuroscience.2015.12.036.

Wang, Y., Deng, F., Jia, Y., Wang, J., Zhong, S., Huang, H., et al. (2018). Disrupted rich club organization and structural brain connectome in unmedicated bipolar disorder. Psychological Medicine, 49, 510-518. https://doi.org/10.1017/ s0033291718001150.

Wang, G. Y., \& Griskova-Bulanova, I. (2018). Electrophysiological activity is associated with vulnerability of internet addiction in non-clinical population. Addictive Behaviors, 84, 33-39. https://doi.org/10.1016/j.addbeh.2018.03.025.

Wang, Y., Wu, L., Wang, L., Zhang, Y., Du, X., \& Dong, G. (2016). Impaired decision-making and impulse control in internet gaming addicts: Evidence from the comparison with recreational internet game users. Addiction Biology, 22(6), 16101621. https://doi.org/10.1111/adb.12458.

Wang, J. H., Zuo, X. N., Gohel, S., Milham, M. P., Biswal, B. B., He, Y. (2011). Graph theoretical analysis of functional brain networks: Test-retest evaluation on short-and long-term restingstate functional MRI data. PloS One, 6(7), e21976. https://doi. org/10.1371/journal.pone.0021976.

Watts, D. J., \& Strogatz, S. H. (1998). Collective dynamics of 'smallworld' networks. Nature, 393, 440-442. https://doi.org/10.1038/ 30918

Wee, C. Y., Zhao, Z., Yap, P. T., Wu, G., Shi, F., Price, T., et al. (2014). Disrupted brain functional network in internet addiction disorder: A resting state functional magnetic resonance imaging study. PloS One, 9(9), e107306. https://doi.org/ 10.1371/journal.pone.0107306.

Xia, M., Wang, J., \& He, Y. (2013). BrainNet viewer: A network visualization tool for human brain connectomics. PloS One, 8 , e68910. https://doi.org/10.1371/journal.pone.0068910.

Xiong, J., \& Yao, L. (2010). The research of event-related potentials in working memory of the juvenile internet addiction. International Conference on E-Health Networking, Digital Ecosystems and Technologies, 1, 93-95. https://doi.org/10.1109/EDT. 2010.5496510.

Xu, P., Xiong, X. C., Xue, Q., Tian, Y., Peng, Y., Zhang, R., et al. (2014). Recognizing mild cognitive impairment based on network connectivity analysis of resting EEG with zero reference. Physiological Measurement, 35(7), 1279-1298. https://doi. org/10.1088/0967-3334/35/7/1279.

Yan, W. S., Li, Y. H., Xiao, L., Zhu, N., Bechara, A., \& Sui, N. (2014). Working memory and affective decision-making in addiction: A neurocognitive comparison between heroin addicts, pathological gamblers and healthy controls. Drug and Alcohol Dependence, 134, 194-200. https://doi.org/10.1016/j. drugalcdep.2013.09.027.

Yang, J., Pu, W., Wu, G., Chen, E., Lee, E., Liu, Z., et al. (2020). Connectomic underpinnings of working memory deficits in schizophrenia: Evidence from a replication fMRI study. Schizophrenia Bulletin, 2(04), 1-11. https://doi.org/10.1093/ schbul/sbz137.

Yao, D. (2001). A method to standardize a reference of scalp EEG recordings to a point at infinity. Physiological Measurement, 22(4), 693-711. https://doi.org/10.1088/0967$3334 / 22 / 4 / 305$.

Young, K. S. (1998). Internet addiction: The emergence of a new clinical disorder. CyberPsychology and Behavior, 1(3), 237-244. https://doi.org/10.1089/cpb.1998.1.237.

Yuan, K., Jin, C., Cheng, P., Yang, X., Dong, T., Bi, Y., et al. (2013). Amplitude of low frequency fluctuation abnormalities in adolescents with online gaming addiction. PloS One, 8(11), e78708. https://doi.org/10.1371/journal.pone.0078708.

Yuan, K., Qin, W., Wang, G., Zeng, F., Zhao, L., Yang, X., et al. (2011). Microstructure abnormalities in adolescents with internet addiction disorder. PloS One, 6(6), e20708. https://doi. org/10.1371/journal.pone.0020708.

Yuan, P., \& Raz, N. (2014). Prefrontal cortex and executive functions in healthy adults: A meta-analysis of structural neuroimaging studies. Neuroscience \& Biobehavioral Reviews, 42, 180-192. https://doi.org/10.1016/j.neubiorev.2014.02.005.

Zhai, J., Luo, L., Qiu, L., Kang, Y., Liu, B., Yu, D., et al. (2017). The topological organization of white matter network in internet gaming disorder individuals. Brain Imaging \& Behavior, 11(6), 1769-1778. https://doi.org/10.1007/s11682-016-9652-0.

Zhang, C., Dougherty, C. C., Baum, S. A., White, T., \& Michael, A. M. (2018). Functional connectivity predicts gender: Evidence for gender differences in resting brain connectivity. Human Brain Mapping, 39, 1-11. https://doi.org/10.1002/hbm.23950.

Zheng, G., Qi, X., Li, Y., Zhang, W., \& Yu, Y. (2018). A comparative study of standardized infinity reference and average reference for EEG of three typical brain states. Frontiers in Neuroscience, 12, 158. https://doi.org/10.3389/fnins.2018.00158. 
Zhou, Y., Li, D., Xian, L., Wang, Y., \& Zhao, L. (2017). Big five personality and adolescent internet addiction: The mediating role of coping style. Addictive Behaviors, 64, 42-48. https://doi. org/10.1016/j.addbeh.2016.08.009.

Zhou, Z., Zhou, H., Li C., \& Wang, J. (2014). Internet addictive individuals share impulsivity and executive dysfunction with alcohol-dependent patients. Frontiers in Behavioral Neuroscience, 8, 288. https://doi.org/10.3389/fnbeh.2014. 00288.
Zhou, Z., Zhou, H., \& Zhu, H. (2015). Working memory, executive function and impulsivity in internet-addictive disorders: A comparison with pathological gambling. Acta Neuropsychiatrica, 28(2), 92-100. https://doi.org/10.1017/neu.2015.54.

Zhu, J., Wang, C., Liu, F., Qin, W., Li, J., \& Zhuo, C. (2016). Alterations of functional and structural networks in schizophrenia patients with auditory verbal hallucinations. Frontiers in $\mathrm{Hu}$ man Neuroscience, 10, 114. https://doi.org/10.3389/fnhum. 2016.00114 . 